\title{
Performance of Exterior Beam-Column Joints with U-Shaped Bars for Different Stirrups Detailing: Numerical Study
}

\author{
Mohamed H. El-Naqeeb ${ }^{1}$, Salah E. El-Metwally ${ }^{2 *}$, Basem S. Abdelwahed ${ }^{3}$ \\ ${ }^{1}$ Teaching Assistant, Structural Engineering Department, Badr University in Cairo (BUC), Cairo, Egypt \\ ${ }^{2}$ Prof. of Structural Concrete, ${ }^{3}$ Lecturer of Structural Engineering, \\ Structural Engineering Department, Mansoura University, El-Mansoura, Egypt \\ *Corresponding author, Email: selmetwally@ mans.edu.eg
}

\begin{abstract}
The relevant detailing of joint reinforcement plays a major role in ensuring adequate performance of reinforced concrete frames in terms of strength and ductility. The reinforcement detailing of joints with U-shaped bars in most common codes is achieved by providing a minimum stirrups reinforcement ratio and a maximum spacing between them; however, the contribution of the cross ties configuration within the joint core in the shear resisting mechanism is not considered. The nonlinear finite element analysis using ABAQUS software has been employed in this study to numerically investigate the influence of different joint reinforcement configurations on joint performance. Four sets of beam-column connections with different joint stirrups configurations have been modeled for achieving this purpose, considering two validated experimentally tested beam-column connections as reference. This study reveals that achieving the codes minimum joint reinforcement ratio using both internal cross ties and outer stirrups instead of outer stirrups only is more efficient in terms of joint strength and deformation capacity which indicates that the contribution of the cross ties considering its shape and location in the shear strength resistance should be considered. It has been observed that both the joint strength and deformation capacity have been significantly improved with the use of two closed rectangular cross ties or one polygon cross tie within the joint region. Hence, those two layouts are considered as the most practical solutions in which the maximum spacing between the stirrups can be considerably increased without affecting the joint performance. The results also proved that the induced stress in the joint stirrups doesn't necessarily reach their yield strength even at the instant of joint failure. Hence, the yielding assumption for all layers of joint reinforcement in some analytical models and different international codes is unsafe and needs some revision.
\end{abstract}

Keywords: Reinforced concrete frames; Exterior joints; Nonlinear finite element analysis; U-shaped bars; Stirrups detailing; Cross ties; Shear strength; Yielding. 


\section{Introduction}

The convenient performance of reinforced concrete (RC) frames is governed by the proper design and detailing of its components; beams, columns, and joints. Joints should be well designed and detailed to satisfy both the strength and ductility requirements (El-Metwally and Chen, 2017). A lot of damage in different buildings was recorded as a result of the inadequate joints ductility due to improper joint confinement by joint reinforcement, as presented in Fig. 1.

Joint reinforcement is generally provided in the form of transverse reinforcement and intermediate vertical bars. Both of them play an important role in resisting shear stresses within the joint. In addition, they provide a good confinement condition for the compressed concrete in the main diagonal strut and participate in resisting the shear force developed in the truss mechanism, as in Fig. 2 (Paulay et al., 1978). On the other side, Hanson and Connor (1967) and Ugale and Khante (2020) observed that joints without transverse reinforcement can't resist extra loads after advanced stages of reversed cyclic loading and exhibit large displacement with wide cracks.

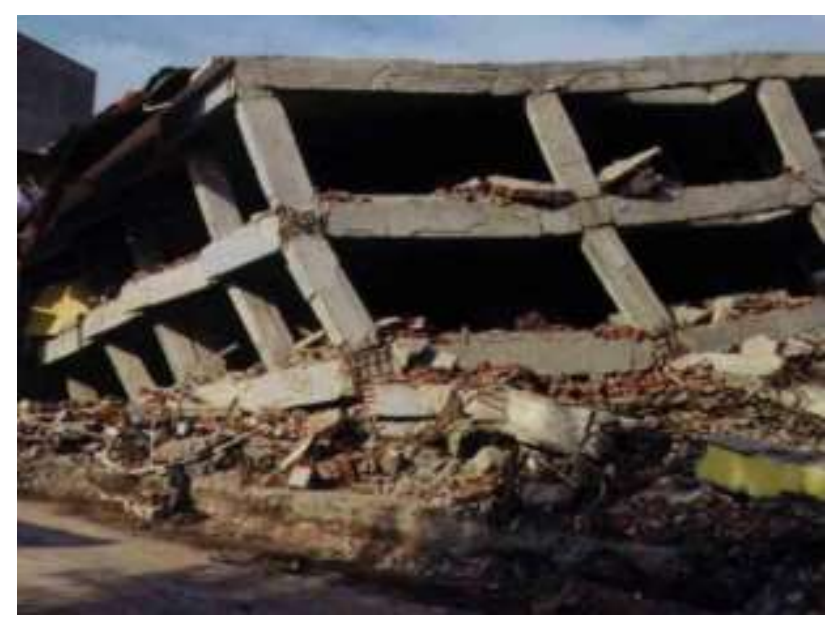

Fig. 1 Beam-column connection failure during Kocaeli earthquake, Turkey (Saatcioglu et al., 2001).

Hwang et al. (2005) studied the role of joint hoops in the shear transfer mechanism in exterior beam-column joints. They indicated that the main function of the joint hoops is to work as a tension tie and limit the cracks' width. On the other side, Kuang and Wong (2011) noted that the performance of joints with horizontal stirrups ratios greater than $0.4 \%$ did not significantly improve for this excess of reinforcement. Najafgholipour and Arabi (2020) conducted a nonlinear finite element study to investigate the influence of two different stirrups layouts within the joint core, as in Fig. 3. For joints with expected shear failure mode, they found that the provision of four legs straight tie improves both the joint strength and deformation capacity, while, the deformation capacity is only improved in the case of joints with beam failure mode. Ata et al. (2003) compared the performance of exterior beam-column joint using different stirrups shapes within the joint core. They observed that the provision of additional diamond shape cross tie and vertical bar within the joint panel improved the joint capacity by $31 \%$ as a result of the increased number of the developed struts. 


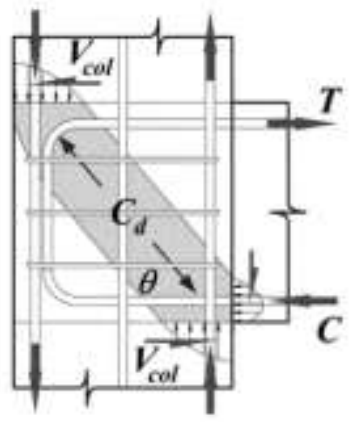

(a)

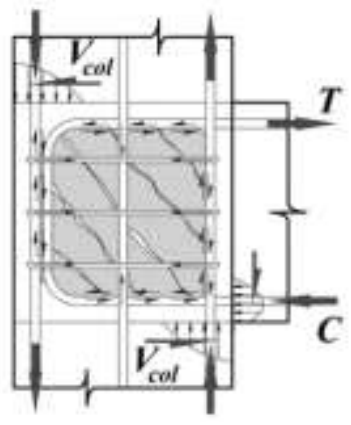

(b)

Fig. 2 Shear resisting mechanisms (Paulay et al., 1978): (a) diagonal strut mechanism; and (b) truss mechanism.

Recently, some studies investigated the effect of nontraditional joint reinforcement detailing. For instance, the use of inclined crossbars within the joint region, as in Figs. 4a and 4b, with this option, Lu et al. (2012) and Rajagopal and Prabavathy (2014) recorded a significant improvement in the joint's performance. Also, the use of square spiral confinement instead of square ties, as shown in Fig. 4c was investigated by Asha and Sundararajan (2018) and an improvement in the connection performance in terms of high joint capacity and less joint shear distortion was observed.

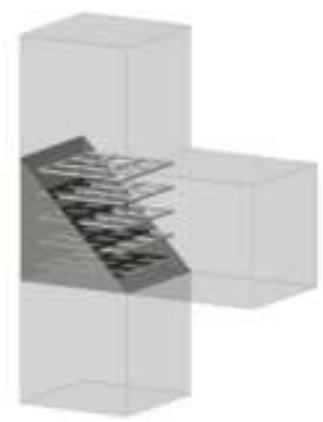

(a)

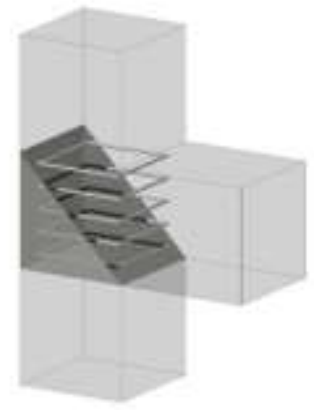

(b)

Fig. 3 Considered joint stirrups layout in Najafgholipour and Arabi (2020) study: (a) with cross ties; and (b) without cross ties.

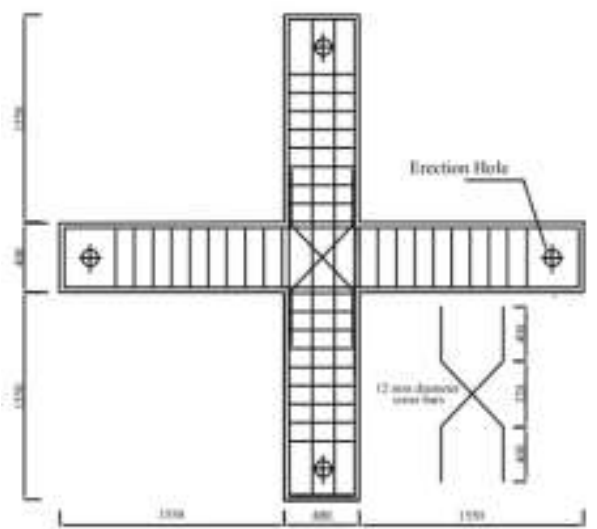

(a)

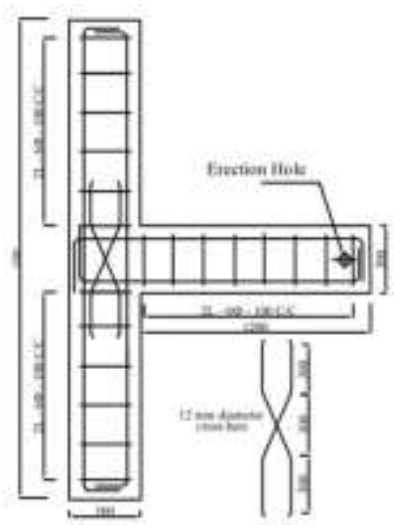

(b)

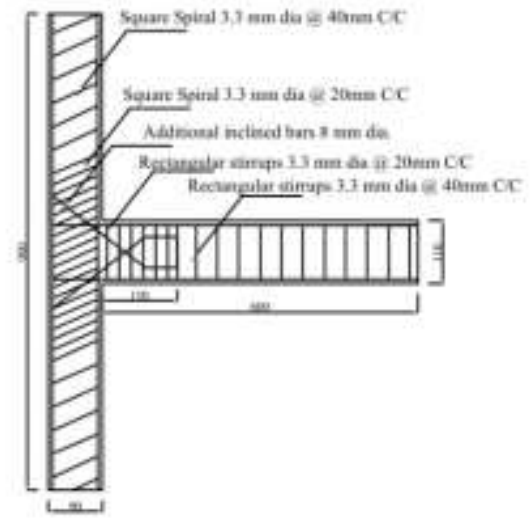

(c)

Fig. 4 Nontraditional joint reinforcement: (a) Lu, et al. (2011) details; (b) Rajagopal and Prabavathy (2013) details; and (c) Asha and Sundararajan (2018) details. 
International codes (ACI 318-19, ACI 352R-02, and Eurocode 8) specified a minimum transverse reinforcement within the joint panel in each direction with a maximum spacing between them as presented in table 1 . The performance of exterior joints designed according to the ACI 352R-02 and Eurocode 8 was experimentally investigated by Tsonos (2007). All specimens were designed to have sufficient joint strength, in spite of that, some specimens exhibited joint failure mode. He observed a weak performance with brittle failure scenarios, and he recommended that some of these codes assumptions should be modified.

Table 1 Codes provisions

\begin{tabular}{|c|c|c|c|c|c|}
\hline Item & \multicolumn{3}{|c|}{ ACI 318-19 } & ACI 352-02R & EC-8 \\
\hline \multirow{2}{*}{$\mathrm{A}_{\text {str min }}$} & $\begin{aligned} P_{u} & \leq 0.3 A_{g} f_{c}^{\prime} \\
& \text { and } \\
f_{c}^{\prime} & \leq 70 \mathrm{MPa}\end{aligned}$ & $\begin{array}{l}\text { Max of a, } \\
\text { b }\end{array}$ & \multirow{2}{*}{$\begin{array}{l}0.3 \frac{s_{h} b_{c} f_{c}^{\prime}}{f_{y h}}\left[\frac{A_{g}}{A_{c}}-1\right] \\
0.09 \frac{s_{h} b_{c} f_{c}^{\prime}}{f_{y h}} \\
0.2 K_{f} k_{n} \frac{s_{h} b_{c} P_{u}}{f_{y h} A_{c}}\end{array}$} & \multirow{2}{*}{$\begin{array}{c}0.3 \frac{s_{h} b_{c}^{\prime \prime} f_{c}^{\prime}}{f_{y h}}\left[\frac{A_{g}}{A_{c}}-1\right] \text { or } \\
0.09 \frac{s_{h} b_{c}^{\prime \prime} f_{c}^{\prime}}{f_{y h}}\end{array}$} & \multirow{2}{*}{$\left(\frac{\left(\frac{v_{j h d}}{b_{j} h_{j c}}\right)^{2}}{f_{c t d}+v_{d} f_{c d}}-f_{c t d}\right)\left(\frac{b_{j} h_{j w}}{f_{y w d}}\right)$} \\
\hline & $\begin{array}{c}P_{u}> \\
0.3 A_{g} f_{c}^{\prime} \text { or } \\
f_{c}^{\prime}>70 \mathrm{MPa}\end{array}$ & $\begin{array}{c}\text { Max of a, } \\
\text { b, c }\end{array}$ & & & \\
\hline $\mathrm{S}_{\max }$ & \multicolumn{3}{|c|}{ Min of $\frac{b_{c}}{4}, 6 d_{b}, 150 \mathrm{~mm}$} & $\begin{array}{c}\text { Min of } \frac{b_{c}}{4}, 6 d_{b}, \\
150 \mathrm{~mm}\end{array}$ & Min of $\frac{b_{o}}{2}, 8 d_{b}, 175 \mathrm{~mm}$ \\
\hline
\end{tabular}

$\mathrm{A}_{\text {str min }}$ is the minimum stirrups area, $\mathrm{S}_{\text {max }}$ is the maximum spacing between the stirrups, $s_{h}$ is the spacing between the stirrups, $b_{c}^{\prime \prime}$ is the column breadth in the considered direction, $f_{y h}$ is the yield stress of the stirrups, $A_{g}$ is the joint gross area, $A_{c}$ is the core area of the joint, $b_{c}$ is the minimum dimension of the column, $V_{j h d}$ is the joint horizontal shear force, $v_{d}$ is the column axial stress level which is equal to $\left(P / A_{c} f_{c d}\right), f_{c d}$ is the design strength of concrete in compression, $f_{c t d}$ is the design strength of concrete in tension,,$b_{o}$ is the minimum dimension of the concrete core, and $d_{b}$ is the beam bar diameter.

In this study, the nonlinear finite element analysis is utilized to investigate the effect of joint stirrups configuration on the performance of exterior beam-column connections. The analysis is performed using the nonlinear finite element software ABAQUS, where different nonlinearity sources can be considered effectively. The analysis accuracy is verified by two experimental tests. In order to achieve the study objective, nineteen beam-column connections with different configurations of joint stirrups have been modeled. The analysis results show that the joint performance, in terms of joint strength and deformation capacity, is improved with the provision of cross ties. The results also indicate that the contribution of the cross ties considering their shape and location in the shear strength resistance should be considered.

\section{Experimentally Tested Exterior Beam-Column Connections for Calibration}

A specimen of exterior beam-column connection without joint reinforcement named SP-6, Fig. 5a, tested by (Al-Osta et al., 2018) and another specimen with joint reinforcement named Jo, Fig. 5b, tested by (Mahmoud et. al, 2014) have been selected for the verification of the adequacy of the nonlinear finite element analysis for modeling exterior beam-column connection. Both connections were tested under the action of monotonic loads. The test consisted of two stages; stage one, the column load of $1050 \mathrm{kN}$ and $200 \mathrm{kN}$ was applied at the upper end of the column for specimen SP-6 
and Jo, respectively. After the end of the first stage, the beam was loaded using a second hydraulic jack. In specimen SP-6, the beam load was applied downwards while in specimen Jo, the beam load was applied upwards. A high reinforcement ratio was provided in the beam of specimen SP-6 to avoid the beam reinforcement yielding. In specimen SP-6, the column has a length of $1200 \mathrm{~mm}$ with a cross-section of $200 \times 250$ $\mathrm{mm}$ and reinforced with $6 \$ 20$ and the beam clear length is $900 \mathrm{~mm}$ with a crosssection of $200 \times 250 \mathrm{~mm}$ and equal reinforcement at the top and bottom $4 \$ 20$. For specimen Jo, the column has a length of $2300 \mathrm{~mm}$ with a cross-section of $200 \times 300$ $\mathrm{mm}$ and reinforced with $4 \$ 16$ and the beam clear length is $900 \mathrm{~mm}$ with a crosssection of $200 \times 300 \mathrm{~mm}$ and reinforced with $2 \$ 12$ and $3 \phi 16$ as top and bottom reinforcemement, respectively. The beam bars of specimen SP-6 were anchored by Ubars and of specimen Jo by L-bars. The details of the connections, reinforcement and material properties, are summarized in Table 2.

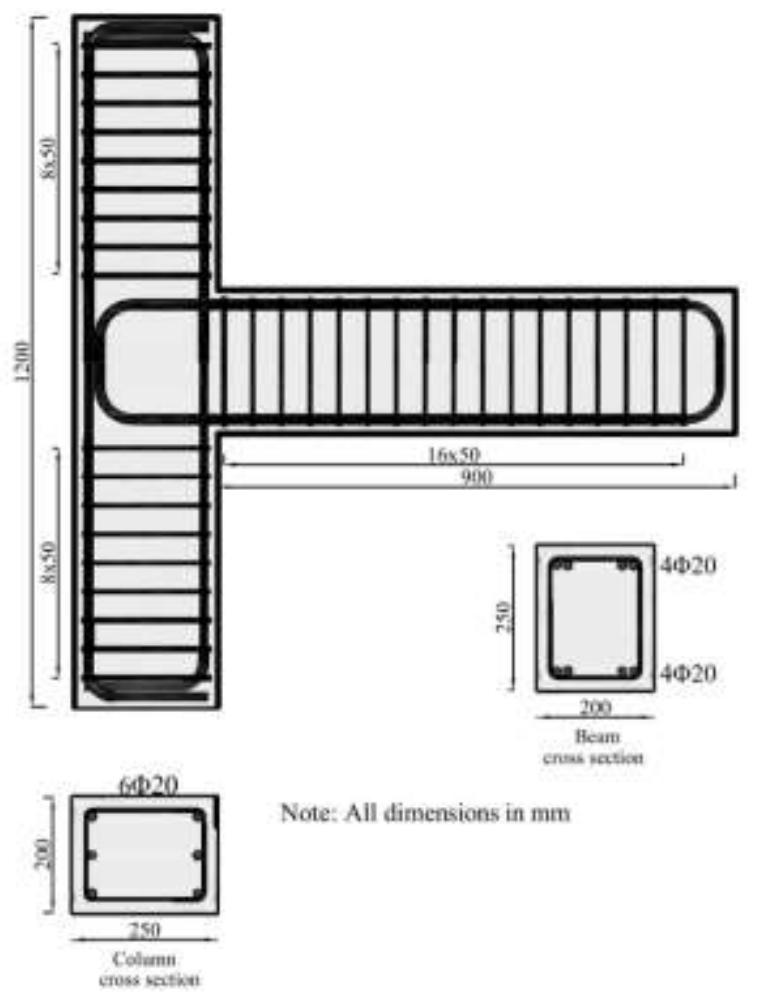

(a)

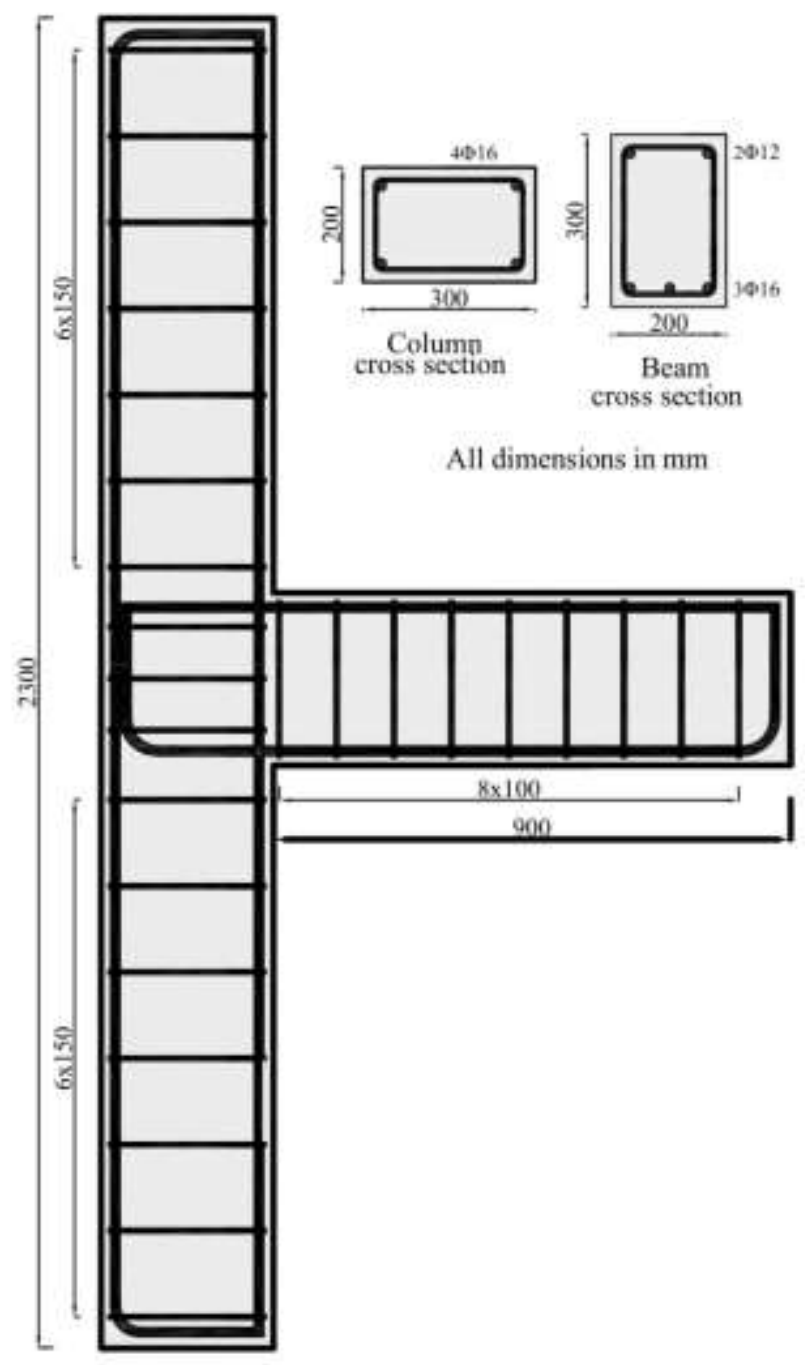

(b)

Fig. 5 Specimens details: (a) Specimen SP-6 (Al-Osta et al., 2018); and (b) Specimen Jo (Mahmoud el al., 2014). 
Table 2 Specimens details

\begin{tabular}{|c|c|c|c|c|c|c|c|c|}
\hline \multirow{2}{*}{ Specimen } & \multirow{2}{*}{$\begin{array}{c}\boldsymbol{f}_{\boldsymbol{c}}^{\prime} \\
(\mathbf{M P a})\end{array}$} & \multicolumn{2}{|c|}{$\boldsymbol{f}_{\boldsymbol{y}}$ (MPa) } & \multicolumn{2}{c|}{ Column Reinforcement } & \multicolumn{3}{c|}{ Beam Reinforcement } \\
\cline { 3 - 9 } & Main & Transverse & Longitudinal & Stirrups & Tension & Compression & Stirrups \\
\hline SP-6 & 30 & 605 & 580 & $6 \phi 20$ & $\begin{array}{c}1 \phi 8 @ 50 \\
\mathrm{~mm}\end{array}$ & $4 \phi 20$ & $4 \phi 20$ & $1 \phi 8 @ 50 \mathrm{~mm}$ \\
\hline Jo & 20.3 & 400 & 240 & $4 \phi 16$ & $\begin{array}{c}1 \phi 8 @ 150 \\
\mathrm{~mm}\end{array}$ & $4 \phi 16$ & $2 \phi 12$ & $\begin{array}{c}1 \phi 8 @ 100 \mathrm{~m} \\
\mathrm{~m}\end{array}$ \\
\hline
\end{tabular}

\section{Nonlinear Finite Element Analysis}

ABAQUS software provides an extensive library for the materials and elements, enabling the accurate simulation of the complex nonlinear behavior of concrete structures. The concrete damage plasticity (CDP) model is employed in this study to simulate the concrete material behavior. This model is a continuum, plasticity-based damage model in which two major failure mechanisms are considered for the concrete elements; concrete crushing and tensile cracking. This concrete material model has been widely used in several studies (Najafgholipour and Arabi, 2020 and Dabiri et al., 2020) and has shown its ability for accurate simulation of the nonlinear behavior of exterior beam-column connections. Different parameters are required to be defined for this model; the plasticity parameters, concrete uniaxial behavior in both compression and tension, and the scaler damage parameters in both compression and tension.

The major plasticity parameters for the CDP model, as presented in table 3 , are the dilation angel of concrete, the eccentricity and its default value is 0.1 , which indicates that the material's dilation angle remains approximately constant over a broad variety of confining pressure stress values, the ratio between the second stress invariant on the tensile meridian and the compressive meridian, $0.5<K_{c} \leq 1$, at the initial yield, this condition has to be met, the ratio between the concrete biaxial compressive strength, $\sigma_{b 0}$, and the concrete uniaxial compressive strength, $\sigma_{c 0}$, and its default value is 1.16 , and the viscosity parameter, $\mu$, which is an effective parameter for resolving the convergence problems for the material models with a strain-softening behavior (Simulia, 2014). The used values of these parameters, table 3, are chosen according to the recommended values given by Najafgholipour and Arabi (2020) and Simulia (2014), which gave the best fit with the experimental results.

Table 3 Plasticity parameters used in ABAQUS

\begin{tabular}{|c|c|c|c|c|}
\hline Dilation angel & Eccentricity & $\mathbf{K c}$ & $\boldsymbol{\sigma}_{\boldsymbol{b} \mathbf{0}} / \boldsymbol{\sigma}_{\boldsymbol{c} \mathbf{0}}$ & Viscosity parameter \\
\hline 36 & 0.1 & 0.667 & 1.16 & 0.00035 \\
\hline
\end{tabular}

The concrete uniaxial behavior in compression is simulated using the stressstrain model developed by Thorenfeldt et al. (1987), Fig. 6a. This model is described by Eq. (1) in which, $f_{c}^{\prime}$ is the cylinder strength, $\varepsilon_{0}$ is the strain corresponding to a stress equal to $f_{c}^{\prime}$, and $\mathrm{n}$ and $\mathrm{k}$ are parameters based on the concrete strength (Wight and MacGregor, 2012). Moreover, the stress strain model proposed by Aslani and Jowkarmeimandi (2012), Fig. 6b, is used for the simulation of the behavior of concrete in tension, where the ascending part assumes a linear relation until reaching the concrete tensile strength $f_{t}$ which takes a value of $0.62 \sqrt{f_{c}^{\prime}}$ according to the ACI 318- 
19 and a corresponding strain $\varepsilon_{t o}$ while the descending part is be described by Eq. (2).

$\frac{f_{c}}{f_{c}^{\prime}}=\frac{n\left(\frac{\varepsilon_{c}}{\varepsilon_{0}}\right)}{n-1+\left(\frac{\varepsilon_{c}}{\varepsilon_{0}}\right)^{n k}}$

$\sigma_{t}=f_{t}\left(\frac{\varepsilon_{t o}}{\varepsilon_{t}}\right)^{0.85}$

The scaler damage parameters in compression $d_{c}$ and in tension $d_{t}$ are only introduced to the model in the descending portion of the stress-strain curve as suggested by Jankowiak and Lodygowski (2005), according to Eqs. (3) and (4) and as shown in Fig.6.

$$
\begin{aligned}
& d_{c}=1-\frac{f_{c}}{f_{c}^{\prime}} \\
& d_{t}=1-\frac{\sigma_{t}}{f_{t}}
\end{aligned}
$$

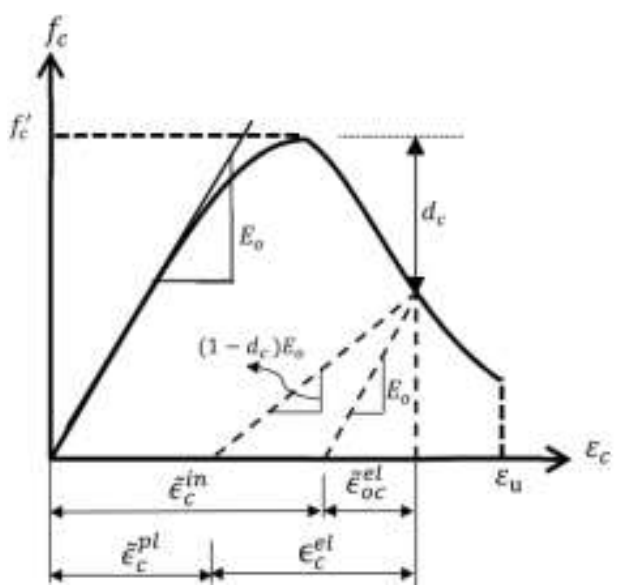

(a)

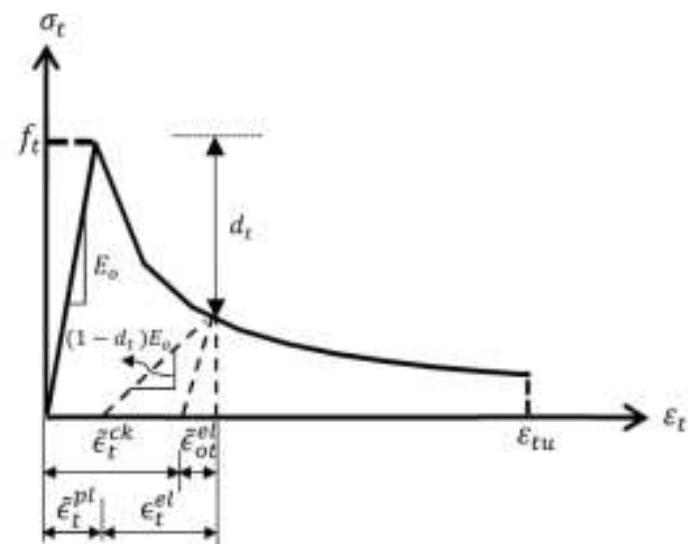

(b)

Fig. 6 Definition of concrete behavior: (a) in compression; and (b) in tension.

The uniaxial stress-strain relation of concrete in compression is introduced to the CDP model in terms of an inelastic strain $\tilde{\epsilon}_{c}^{i n}$;

$\tilde{\epsilon}_{c}^{i n}=\epsilon_{c}-\tilde{\epsilon}_{o c}^{e l}, \tilde{\epsilon}_{o c}^{e l}=\frac{f_{c}}{E_{o}}$

and the corresponding stress $f_{c}$ where $E_{o}$ is the initial elastic modulus which is taken as $4700 \sqrt{f_{c}^{\prime}} \mathrm{MPa}$ according to the ACI $318-19$.

The input data for the damage parameter $d_{c}$ is used to automatically convert the inelastic strain $\tilde{\epsilon}_{c}^{i n}$ into plastic stain $\tilde{\epsilon}_{c}^{p l}$ as follows;

$\tilde{\epsilon}_{c}^{p l}=\tilde{\epsilon}_{c}^{i n}-\frac{d_{c}}{\left(1-d_{c}\right)} \frac{\sigma_{c}}{E_{0}}$

Similarly, the stress-strain relation in uniaxial tension is defined in terms of a cracking strain $\tilde{\epsilon}_{t}^{c k}$ and the corresponding stress $\sigma_{t}$.

$\tilde{\epsilon}_{t}^{c k}=\epsilon_{t}-\tilde{\epsilon}_{o t}^{e l}$ 
The behavior of steel reinforcement is assumed to be elastic perfectly-plastic. The steel yield stress is taken as the reported value in the experimental program. The steel modulus of elasticity is considered as $E_{S}=200 \mathrm{GPa}$, and the Poisson's ratio = 0.3. In ABAQUS, the steel reinforcement is modeled as one-dimensional bars embedded inside the concrete elements using the embedment constraint and no bondslip relation is defined between the concrete and steel reinforcement.

The concrete and the loading plate are modeled using the eight nodded 3D hexahedral element C3D8R. This element has three translation degrees of freedom at each node with a reduced integrated continuum hourglass control option. While the steel reinforcement is modeled using a 2- node T3D2 element that has two translation degrees of freedom at each node.

\section{Analysis Verification}

The geometric models for the tested specimens, employed for the analysis verification, are shown in Fig. 7, where a small uniform mesh size of $25 \mathrm{~mm}$ is used. The boundary conditions are applied to the top surface of the column, $U_{x}=U_{y}=0$, and at the bottom surface, $U_{x}=U_{y}=U_{z}=0$, which simulate the boundary conditions of the experimental test setup. Two separated load steps are generated; step one starts with applying the column axial stress at the upper surface of the column. In the second step, the beam load is introduced using a controlled displacement at a reference point in the center of the beam loading plate. This reference point is interactive with the upper coupling nodes of the loading plate using coupling constraint, while a full bond between the contacted surfaces between the loading plate and the beam is assumed by using a tie constraint.

The comparison between the load-deflection curves of the experimentally tested specimens and the numerical models is shown in Fig. 8 in terms of the beam end or tip load-deflection relation. The predicted peak loads obtained from the numerical modeling for specimens SP-6 and Jo are $64.6 \mathrm{kN}$ and $79.1 \mathrm{kN}$, respectively, while the corresponding measured failure loads are $66 \mathrm{kN}$ and $79.8 \mathrm{kN}$.

The visualization of the cracks in the numerical model can be recognized by plotting the plastic strain contours (Simulia, 2014). A comparison between the crack patterns is presented in Fig. 9. For specimen SP-6, the first crack within the joint occurred at $45.0 \mathrm{kN}$ in the experimental test while the predicted cracking load was $44.4 \mathrm{kN}$. The observed mode of failure of the specimen was a joint failure, as depicted from the numerical model, Figs. 9a and 9b, with approximately vertical cracks localized within the joint core and some cracks extended to the upper column. On the other side, the crack initiation of specimen Jo at the tension side of the beam during the experimental program was recognized at a vertical load of $10.0 \mathrm{kN}$ while the diagonal cracks within the joint region began to initiate at a beam load of $45.0 \mathrm{kN}$. Finally, the specimen failed due to beam flexural failure, Fig 9c. The crack visualization of the numerical model, Fig. 9d, indicates that also the numerical model exhibited the same failure mode with a typical crack pattern. The results clearly show the accuracy of the proposed numerical model for the considered exterior beamcolumn connections. 


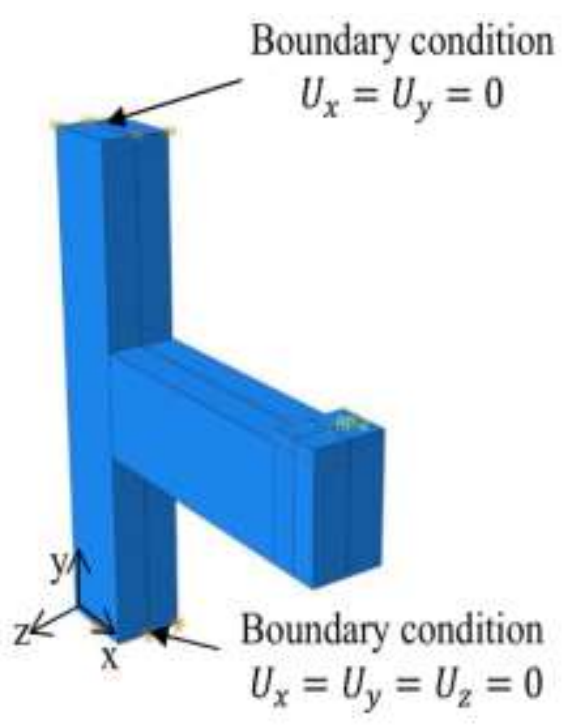

(a)

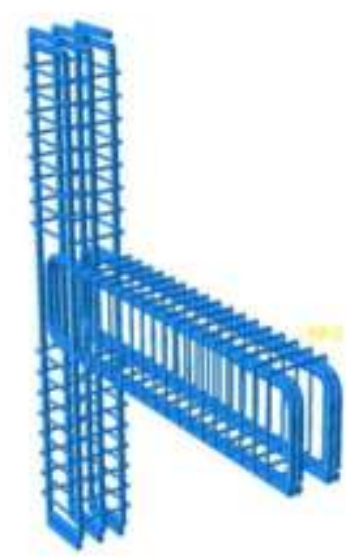

(d)

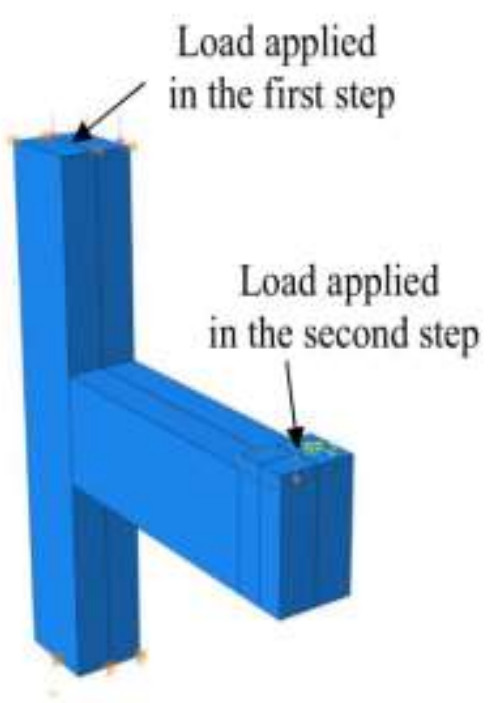

(b)

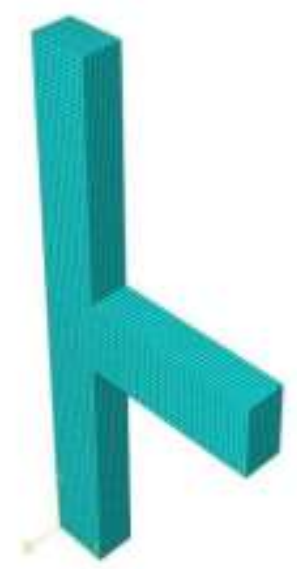

(e)

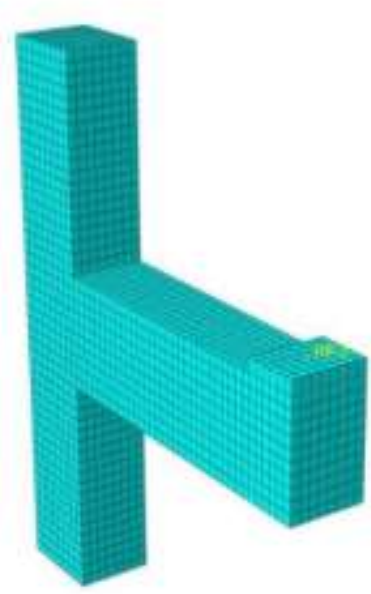

(c)

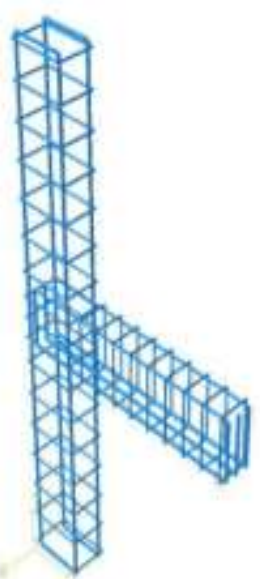

(f)

Fig. 7 Numerical models: (a) boundary conditions; (b) applied loads; (c) meshing of specimen SP-6; (d) reinforcement of specimen SP-6; (e) meshing of specimen Jo; and (f) reinforcement of specimen Jo
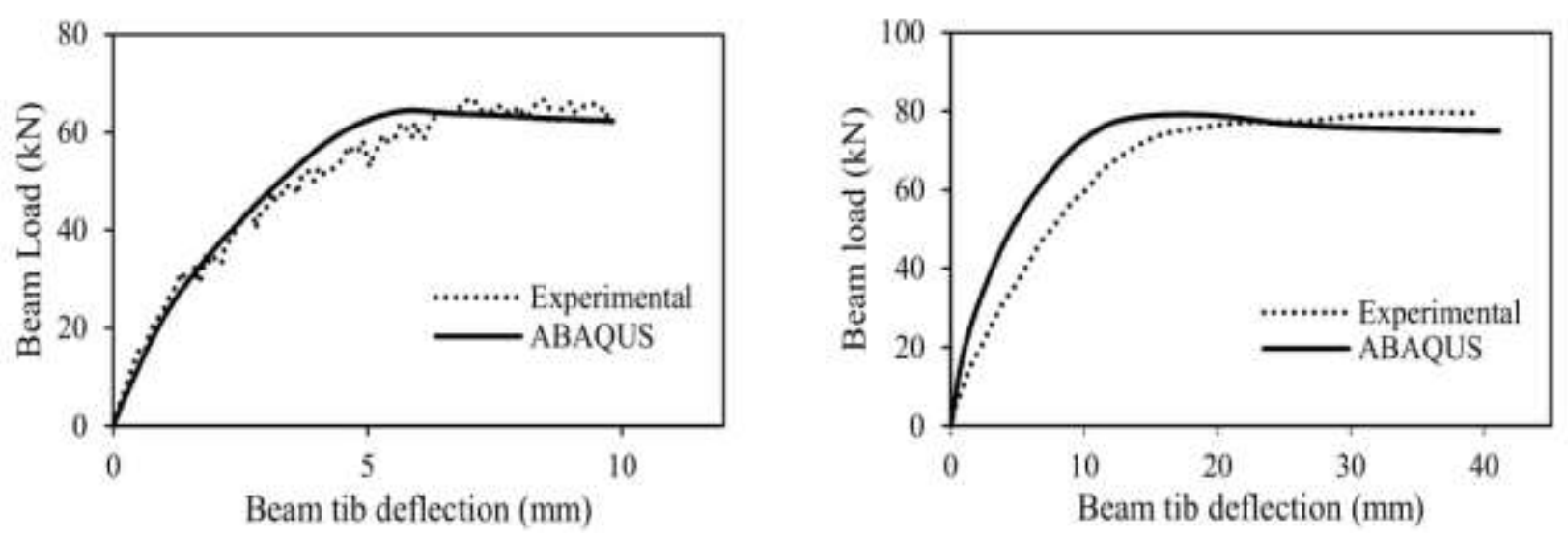

Fig. 8 Load-deflection curve of the tested specimens: (a) specimen SP-6; and (b) specimen Jo. 


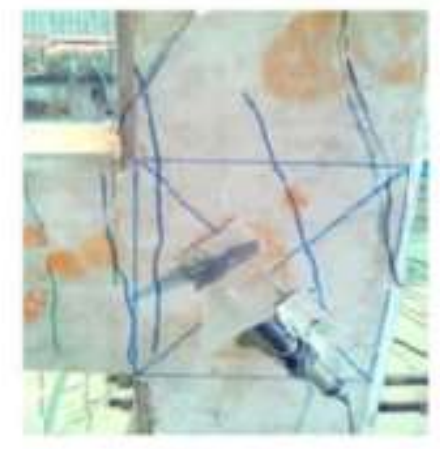

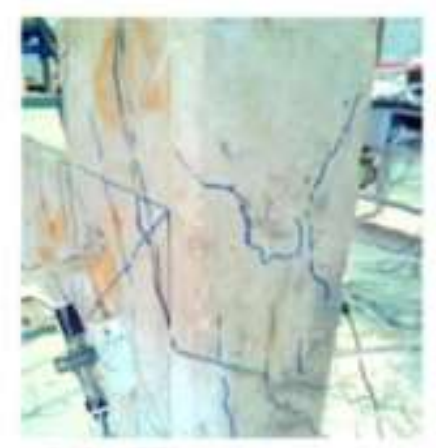

(a)

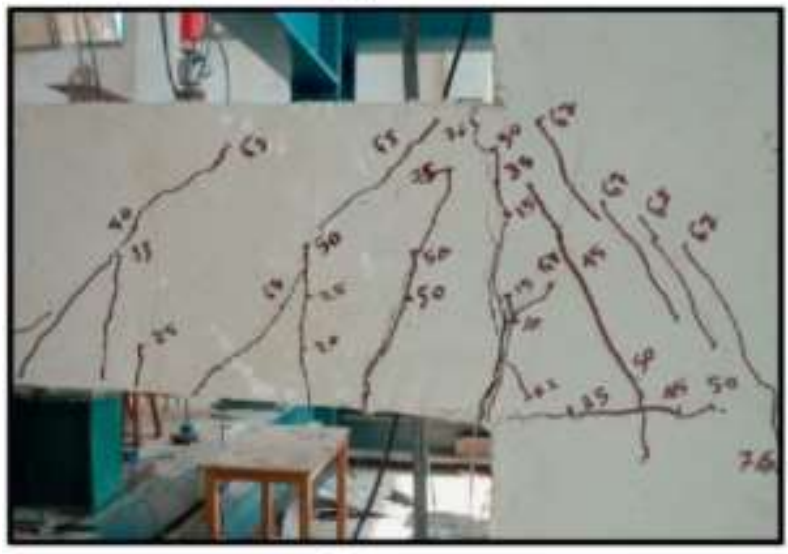

(c)

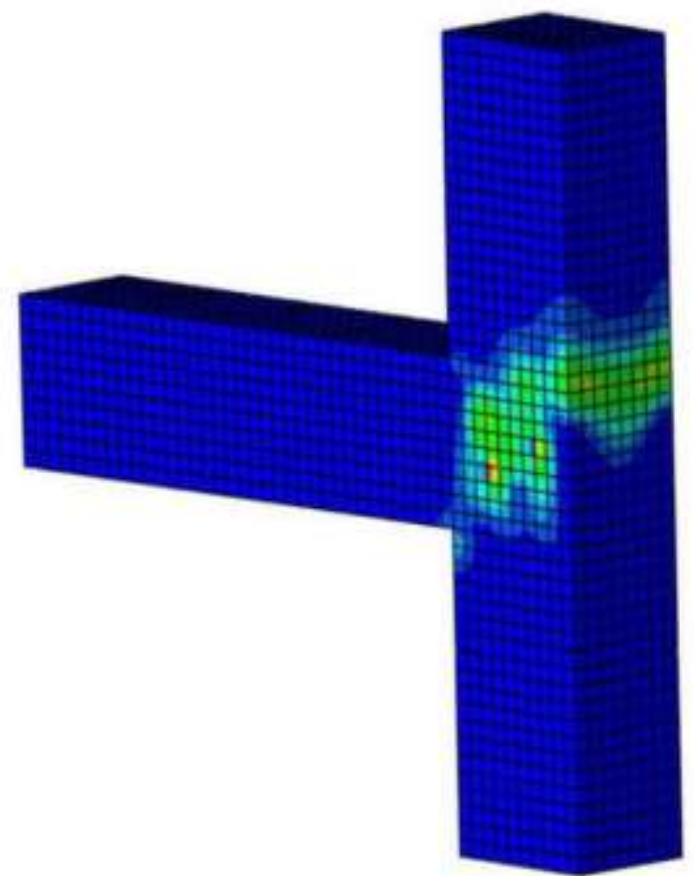

(b)

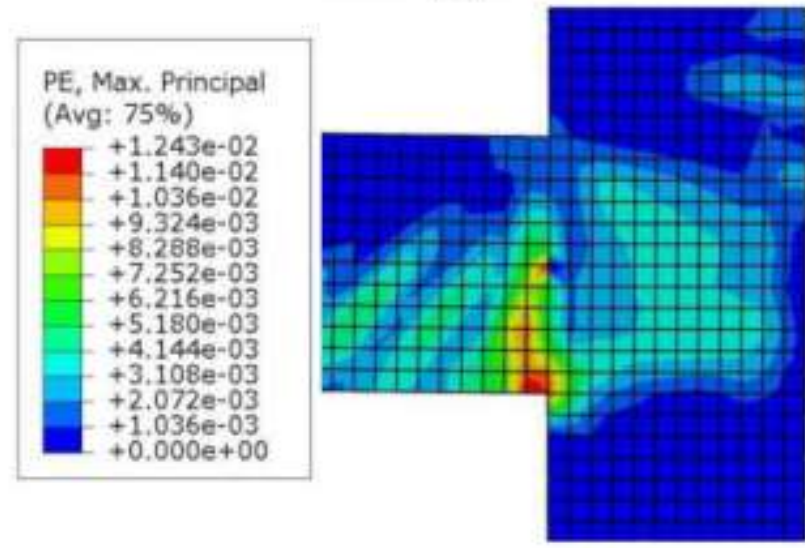

(d)

Fig. 9 Failure modes of the tested specimens: (a), (b) experimental crack pattern and numerical simulation of SP-6; (c), (d) experimental crack pattern and numerical simulation of Jo.

\section{Effect of Traditional Joint Horizontal Stirrups}

The validated model for specimen SP-6 is utilized to investigate the effect of the provision of joint horizontal stirrups. In this section, the effect of providing horizontal outer rectangular 2 legs stirrups according to the ACI 352-02R on the connection performance is investigated. The ACI 352-02 requires a considerable amount of joint reinforcement and narrow spacing between the stirrups layers. The first model in this investigation is the traditional joint reinforcement, Fig. 10, named model O, in which, the joint is reinforced by five layers of $8 \mathrm{~mm}$ single horizontal stirrups which satisfy the ACI-352-02R requirements for both the stirrups minimum area and the maximum spacing between the stirrups. 


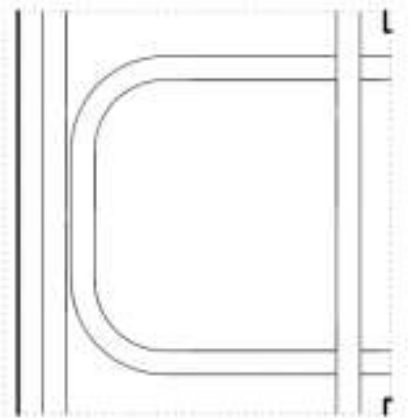

(a)

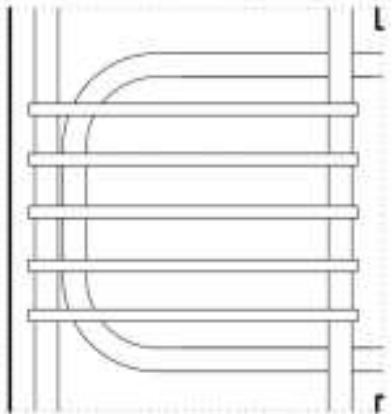

(b)

Fig. 10 Traditional joint reinforcement: (a) reference model SP-6; and (b) Model O.

The load-deflection curve of Model $\mathrm{O}$ is obtained and is compared with the predicted load-deflection curve of the reference calibrated model without any joint reinforcement, Fig. 11. The obtained peak load for Model O is $86.89 \mathrm{kN}$, while for the reference model it is $64.4 \mathrm{kN}$. Clearly, the results show a significant increase, about $35 \%$, of the joint capacity with the provision of joint stirrups. Also, an improvement of the deformation capacity is observed.

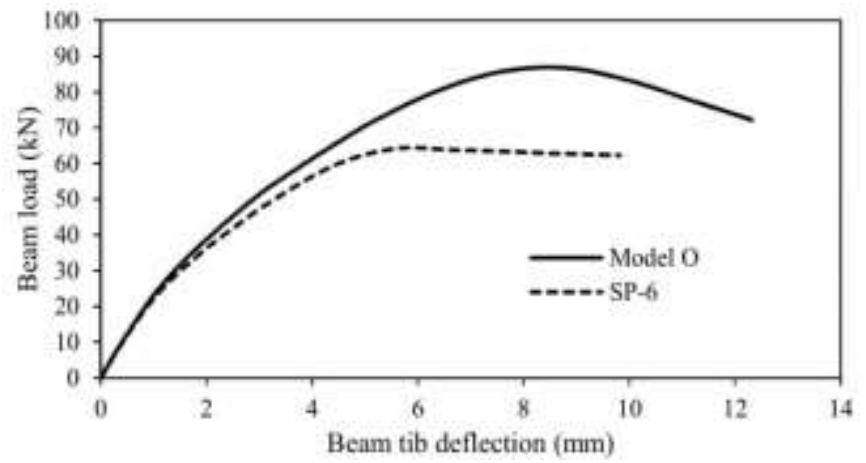

Fig. 11 Effect of traditional joint reinforcement according to the ACI-352-02R.

The nominal joint horizontal shear strength, $V_{n}$, is obtained according to the ACI-352-02R using Eq. (8). This equation does not consider the contribution of the joint horizontal stirrups in resisting the joint horizontal shear force; accordingly, this shear force is only resisted by the concrete strength $V_{c}$. However, the main purpose of the minimum joint stirrups is to achieve a good confinement condition for the main compression strut. On the other side, many available analytical models developed by Vollum and Newman (1999), Bakir and Boduroglu (2002) and Hegger et al. (2003) consider the contribution of the joint stirrups in resisting the horizontal shear force; hence, the joint horizontal shear strength, $V_{j}$, is as given by Eq. (9).

$$
V_{n}=0.083 \gamma A_{j} \sqrt{f_{c}^{\prime}}
$$

$$
V_{j}=V_{c}+V_{s}
$$

where, $V_{c}$ is the concrete resistance and $V_{s}$ is the stirrups contribution.

The obtained joint shear strength, $V_{j}$, from the numerical models for both the reference specimen and the Model $\mathrm{O}$ is compared with the expected values from the 
ACI 352-02R and the aforementioned analytical models, table 4 . It should be noted that the shear strength of specimen SP-6 is lower than the estimate of the ACI 352-02R since the joint does not satisfy the requirement of the Code for horizontal reinforcement. Upon reviewing the results in the table, the necessity to provide joint reinforcement in order to achieve a satisfactory performance of the connection, is clear.

Table 4 Expected joint strength for model SP-6 and model $O$

\begin{tabular}{|c|c|c|c|c|c|c|c|c|c|}
\hline \multirow{3}{*}{ Model } & \multicolumn{5}{|c|}{ Joint shear force $\mathbf{V}_{\mathbf{j}}(\mathbf{k N})$} & & & \\
\cline { 2 - 10 } & Numerical & $\begin{array}{c}\text { ACI } \\
\mathbf{3 5 2 -} \\
\mathbf{0 2 R}\end{array}$ & $\begin{array}{c}\text { Vollum } \\
\text { and } \\
\text { Newman } \\
(\mathbf{1 9 9 9})\end{array}$ & $\begin{array}{c}\text { Hegger } \\
\text { et al. } \\
(\mathbf{2 0 0 3})\end{array}$ & $\begin{array}{c}\text { Bakir and } \\
\text { Boduroglu } \\
(\mathbf{2 0 0 2})\end{array}$ & $\frac{\boldsymbol{V}_{\boldsymbol{j}}}{\boldsymbol{V}_{\boldsymbol{j} \text { ACI }}}$ & $\frac{\boldsymbol{V}_{\boldsymbol{j}}}{\boldsymbol{V}_{\boldsymbol{j} \text { Vollum }}}$ & $\frac{\boldsymbol{V}_{\boldsymbol{j}}}{\boldsymbol{V}_{\boldsymbol{j} \text { Hegger }}}$ & $\frac{\boldsymbol{V}_{\boldsymbol{j}}}{\boldsymbol{V}_{\boldsymbol{j} \text { Bakir }}}$ \\
\hline $\mathrm{SP}-6$ & 231.21 & $272.76^{*}$ & 239.16 & 238.50 & 256.98 & 0.85 & 0.97 & 0.97 & 0.90 \\
\hline $\mathrm{O}$ & 312.00 & 272.76 & 359.43 & 321.75 & 364.90 & 1.14 & 0.87 & 0.97 & 0.86 \\
\hline
\end{tabular}

*The joint does not satisfy the requirement of the Code for horizontal reinforcement.

\section{Effect of Horizontal Stirrups Configuration}

In this section, the traditional shape of joint stirrups provided in Model $\mathrm{O}$ is replaced with stirrups of different shapes to assess the effect of the position and shape of the cross ties on the joint performance. It is worth mentioning that the ACI 352-02R doesn't consider the contribution of the cross ties and its layout in the joint shear strength. Four sets of connection details, named A, B, C, and D with different stirrups layout, as illustrated in Fig. 12, are modeled with only 3 layer of joint stirrups instead of 5 layers as required by the ACI 352-02R. The results of the models of the four sets are presented in terms of the load-deflection curves as in Fig. 13, joint strength, ultimate deformations as in table 5, and induced stresses in the stirrups, Fig. 14.

From the load-deflection curves of the four sets of connection details, presented in Fig. 13, it is noticed that the joint performance in terms of joint strength and deformation capacity is significantly affected by the layout of the horizontal stirrups. The maximum load in each model, corresponding displacement $\Delta_{\mathrm{o}}$, and ultimate displacement $\Delta_{\mathrm{u}}$ measured at $20 \%$ drop of the strength, are summarized in table 5 . The results of the models $\mathrm{A} 1, \mathrm{~B} 1, \mathrm{C} 1$ and $\mathrm{D} 1$ indicate that the provision of different vertical bars passing through the joint core in case of joint with an aspect ratio equal to 1 , does not affect the joint performance when the traditional two legs stirrups are used.

Providing cross ties in the joints parallel to the column width direction is examined by comparing the results of models A2 and B3, for which the obtained peak load is $83.5 \mathrm{kN}$ and $83.62 \mathrm{kN}$, respectively. This observation indicates that the provision of cross ties in this direction has a minor effect on the joint capacity. On the other side, its main benefit is to improve the deformation capacity; the ultimate displacement is $11.89 \mathrm{~mm}$ for $\mathrm{A} 2$ and $13.65 \mathrm{~mm}$ for B3. Also, similar observations are obtained for B1 and B4.

The provision of inner cross ties as in model $\mathrm{C} 2$, doesn't contribute to achieving the minimum reinforcement ratio for the shear resistance mechanism according to the ACI 352-02R where only the stirrups area for the legs penetrating all the column depth are considered; hence, the stirrups reinforcement ratio in both models $\mathrm{C} 1$ and $\mathrm{C} 2$ is 
considered the same according to the Code. However, both the joint strength and deformation capacity have significantly been improved by the provision of this cross tie.

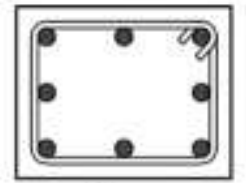

B1

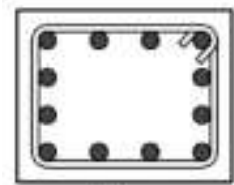

$\mathrm{C} 1$

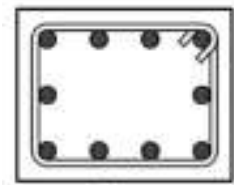

D1

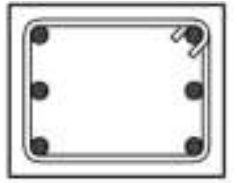

A1

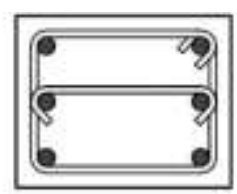

A2

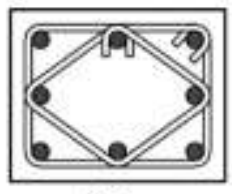

B2

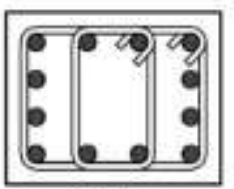

$\mathrm{C} 2$

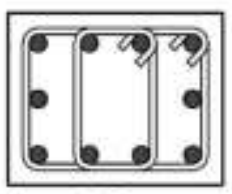

D2

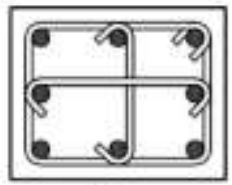

B3

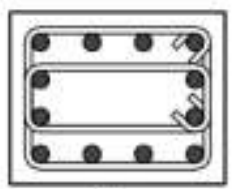

$\mathrm{C} 3$

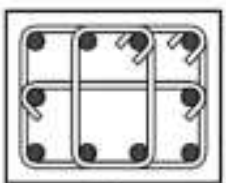

D3

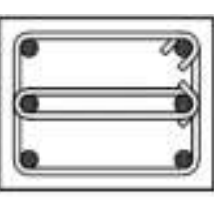

$\mathrm{A} 3$

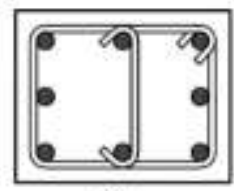

B4
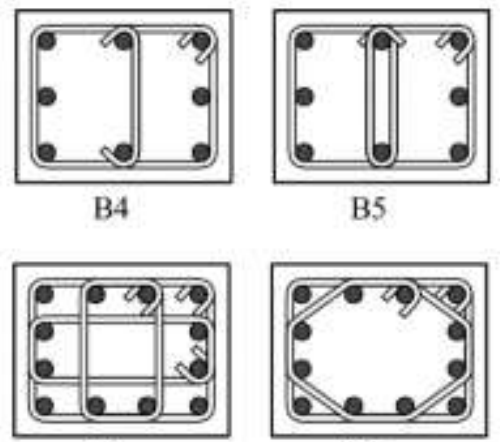

C4
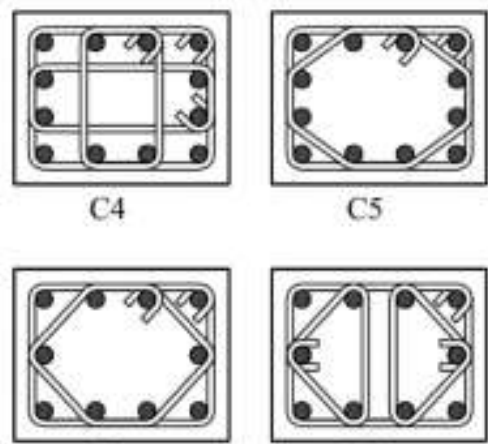

D4

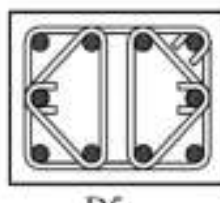

D5

Fig. 12 Different configurations of joint reinforcement. 


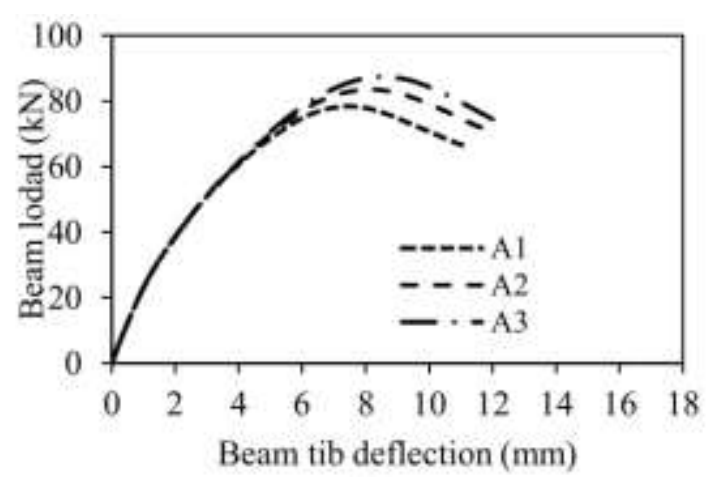

(a)

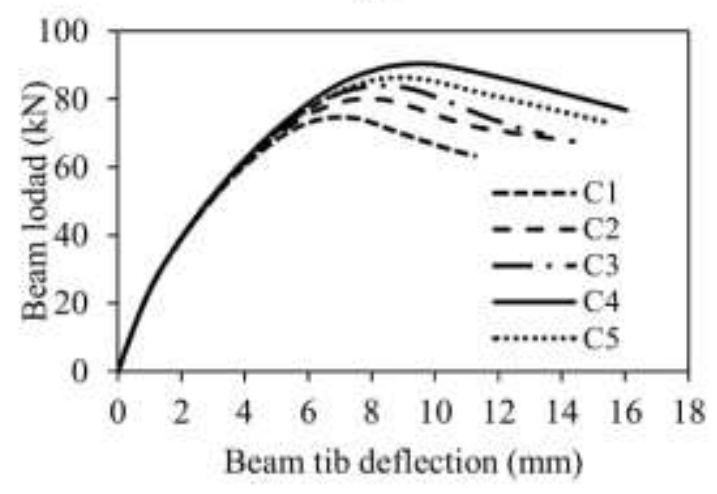

(c)

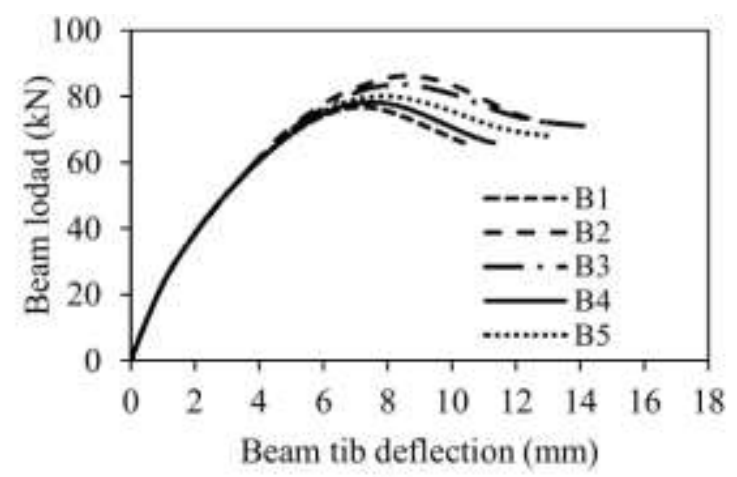

(b)

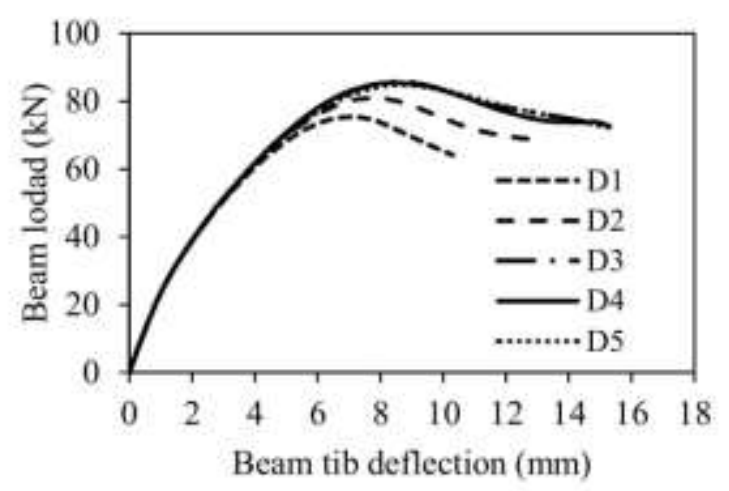

(d)

Fig. 13 Load-deflection curves of numerical models: (a) set A; (b) set B; (c) set C; and (d) set D.

Table 5 Results of the numerical sets

\begin{tabular}{|c|c|c|c|c|}
\hline Set & Model & $\begin{array}{c}\text { Peak load } \\
(\mathrm{kN})\end{array}$ & $\Delta_{0}(\mathbf{m m})$ & $\Delta_{\mathbf{u}}(\mathbf{m m})$ \\
\hline \multirow{3}{*}{ A } & A1 & 77.39 & 7.32 & 11.02 \\
\hline & $\mathrm{A} 2$ & 83.50 & 8.17 & 11.89 \\
\hline & A3 & 87.47 & 8.80 & 12.26 \\
\hline \multirow{5}{*}{ B } & B1 & 76.77 & 7.23 & 10.57 \\
\hline & B2 & 86.17 & 9.35 & 13.79 \\
\hline & B3 & 83.62 & 8.37 & 13.65 \\
\hline & B4 & 78.14 & 7.28 & 11.32 \\
\hline & B5 & 80.07 & 7.88 & 13.10 \\
\hline \multirow{5}{*}{$\mathrm{C}$} & $\mathrm{C} 1$ & 75.65 & 8.91 & 11.24 \\
\hline & $\mathrm{C} 2$ & 80.07 & 11.63 & 14.37 \\
\hline & $\mathrm{C} 3$ & 83.96 & 7.78 & 13.36 \\
\hline & $\mathrm{C} 4$ & 90.65 & 10.58 & 16.03 \\
\hline & $\mathrm{C} 5$ & 86.35 & 9.17 & 15.32 \\
\hline \multirow{5}{*}{$\mathrm{D}$} & D1 & 75.10 & 7.11 & 10.28 \\
\hline & $\mathrm{D} 2$ & 80.90 & 8.85 & 13.35 \\
\hline & D3 & 85.74 & 8.46 & 15.22 \\
\hline & D4 & 85.41 & 11.24 & 15.30 \\
\hline & D5 & 84.79 & 8.80 & 15.42 \\
\hline
\end{tabular}




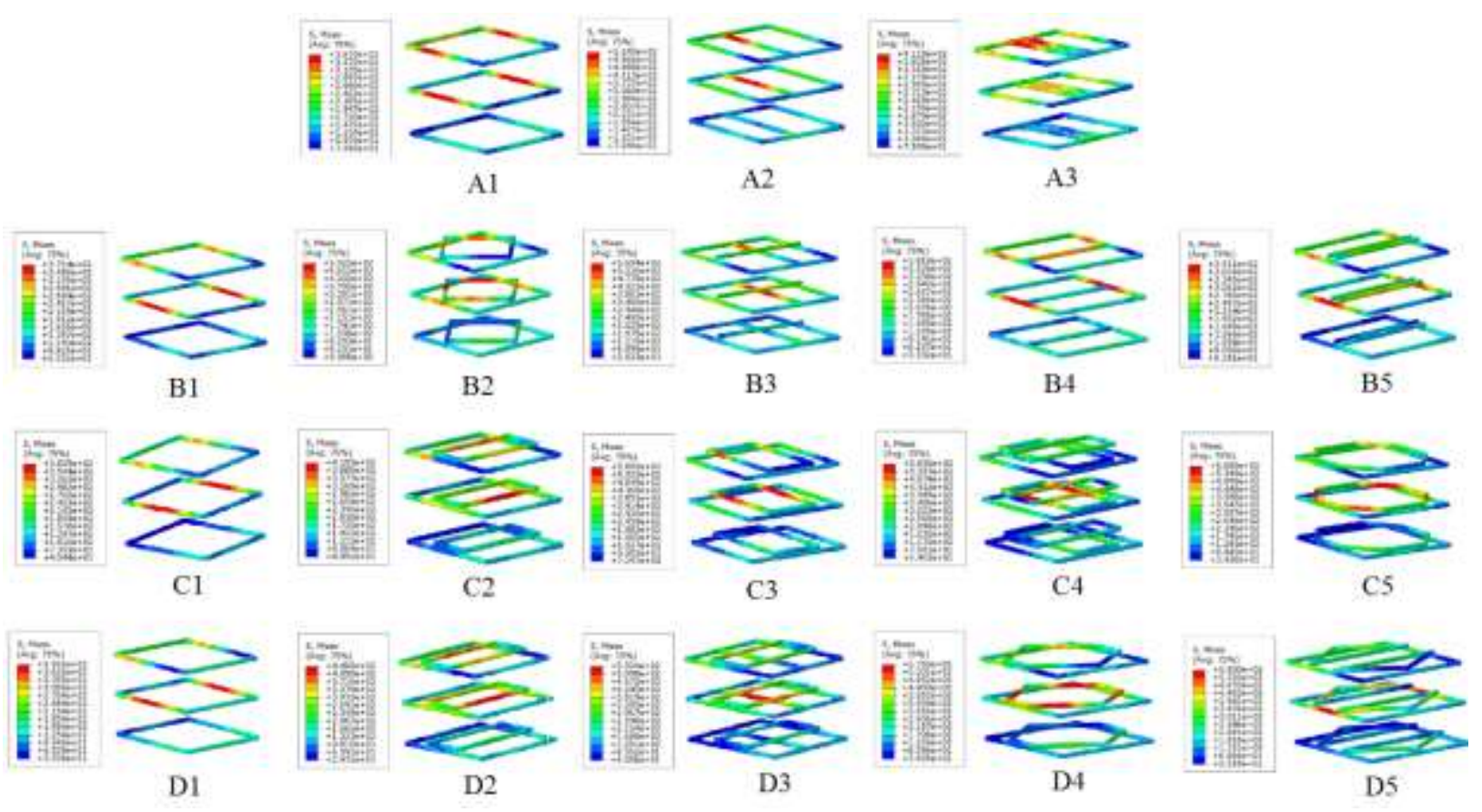

Fig. 14 Induced stress in the joint stirrups.

Models A3, C3, and C5 have the same stirrups area at the critical section of the joint; nevertheless, their obtained peak loads are 87.47, 83.96 and $86.35 \mathrm{kN}$, respectively. Also, the ultimate deformations are 12.26, 13.36, and $15.32 \mathrm{~mm}$, respectively. The deformation capacity has been improved by $25 \%$ for the same stirrups area. This indicates that the shape of the joint stirrups has a direct influence on the deformation capacity.

The superior performance of the connection is obtained when using the layout of model $\mathrm{C} 4$. The nominal strength of this model increased by $8 \%$ compared to that of model C3 and its deformation capacity has been improved by 20\%; though the ACI $352-02 \mathrm{R}$ considers the two models to have the same stirrups area with respect to the joint shear strength mechanism.

The relation between the ultimate displacement and the stirrups volumetric ratio within the joint panel is shown in Fig. 15. Since this ratio accounts for the configuration of the cross ties, the results in the figure indicate that the provision of cross ties, regardless of its orientation, has a significant influence on the deformation capacity. Nevertheless, no considerable increase in the ultimate deformation can be achieved with a volumetric ratio larger than $1.5 \%$. 


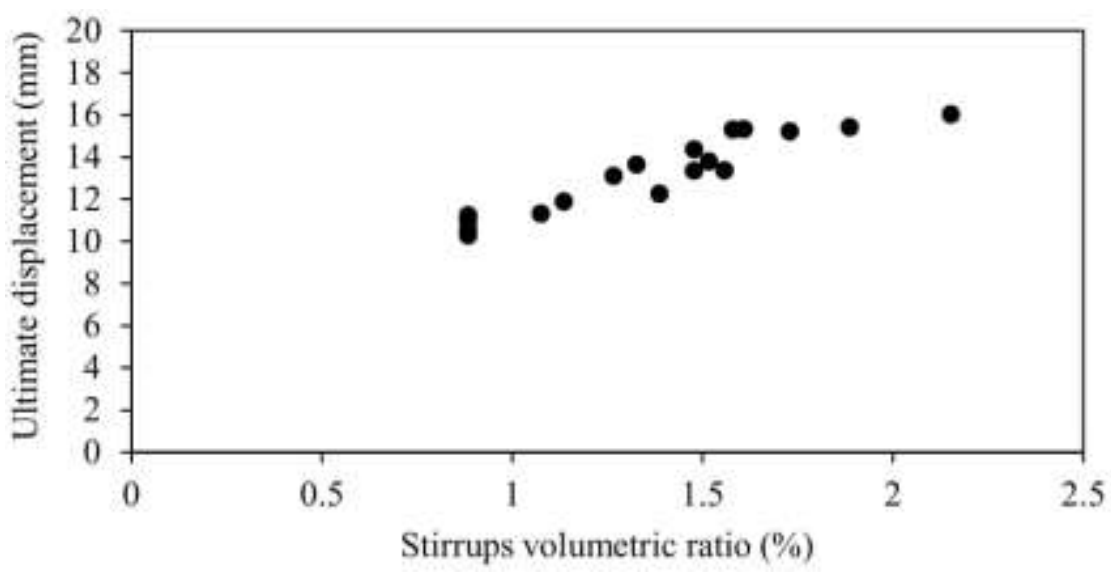

Fig. 15 Effect of stirrups volumetric ratio.

From the stress distribution in the stirrups within the joint panel shown in Fig. 14 , for all models, the maximum stress in each layout is varied, and the location of its maximum value depends on the shape of the stirrup. The provision of the cross ties makes the stirrups work more effectively rather than using outer stirrups only, where the maximum stress value is located in the middle of the straight cross ties and in the inclined parts of the polygon shapes. This observation explains why the joints reinforced by 3 layers with cross ties performs better than the traditional 5 layers of outer stirrups; hence, when the stirrups layout as in models A3, B2, C4, and C5 are used, the maximum spacing between the stirrups according to ACI 352-02R can be considerably increased without a significant effect on the connection performance.

For the most efficient models; A3, B2, C4, C5, a comparison between the predicted joint shear strength and the obtained values according to the ACI-352-02R and models from literature, considering the total cross section area of the stirrups located at the mid distance of the column depth, is summarized in table 6. The maximum stress in the outer stirrups and cross ties in each layer of these models is plotted in Fig. 16.

From the results in Fig. 16, it is noticed that the stress in the stirrups doesn't reach the yield value in all layers, where the stirrup in the middle height has the highest stress while the other layers are less effective, especially those located in the lower third of the joint region. This observation indicates that estimating the joint strength based on the assumption of the stirrups yielding for all layers, as in most available analytical models and codes, is not safe and needs a revision.

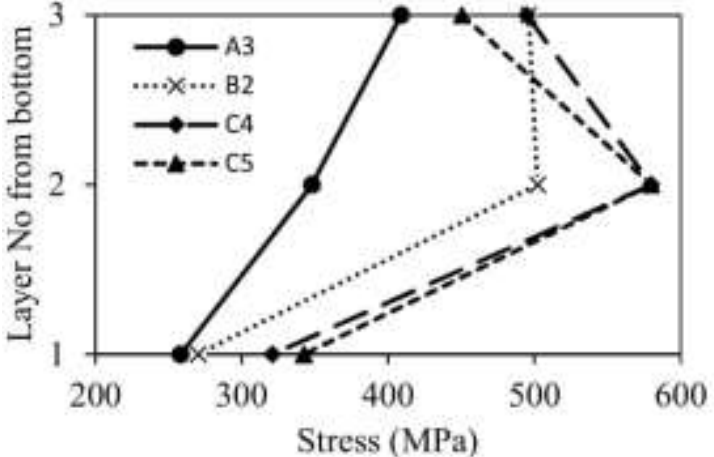

(a)

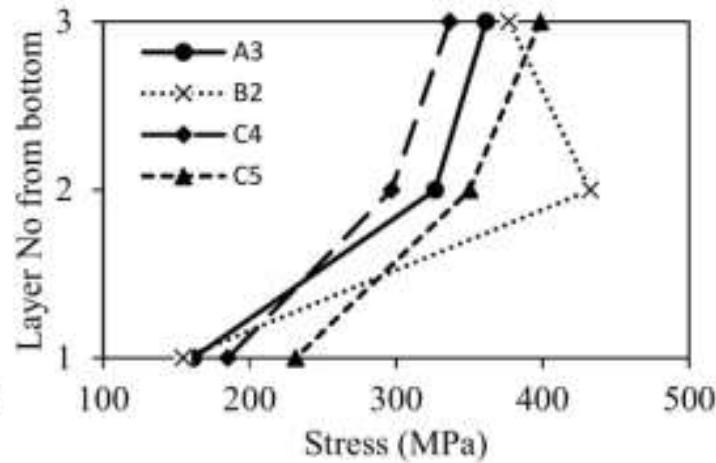

(b)

Fig. 16 Maximum stress in stirrups layers: (a) cross tie; and (b) outer stirrup. 
Table 6 Expected joint strength for the most efficient models

\begin{tabular}{|c|c|c|c|c|c|c|c|c|c|}
\hline \multirow{3}{*}{ Model } & \multicolumn{5}{|c|}{ Joint shear force $V_{j}(\mathrm{kN})$} & \multirow{3}{*}{$\frac{V_{j}}{V_{j A C I}}$} & \multirow[b]{2}{*}{$V_{j}$} & \multirow[b]{2}{*}{$V_{j}$} & \multirow[b]{2}{*}{$\boldsymbol{V}_{j}$} \\
\hline & & ACI & Vollum & Hegger & $\begin{array}{c}\text { Bakir } \\
\text { and }\end{array}$ & & & & \\
\hline & Numerical & $\begin{array}{l}\text { 352- } \\
\text { 02R }\end{array}$ & $\begin{array}{c}\text { and } \\
\text { Newman } \\
(1999)\end{array}$ & $\begin{array}{l}\text { et al. } \\
\text { (2003) }\end{array}$ & $\begin{array}{c}\text { Bodur } \\
\text { oglu } \\
(2002) \\
\end{array}$ & & $V_{j \text { Vollum }}$ & $V_{j \text { Hegger }}$ & $V_{j \text { Bakir }}$ \\
\hline $\mathbf{A 3}$ & 314.04 & 272.77 & 364.23 & 321.75 & 386.50 & 1.15 & 0.86 & 0.98 & 0.81 \\
\hline B2 & 309.37 & 272.77 & 364.23 & 321.75 & 386.50 & 1.13 & 0.85 & 0.96 & 0.80 \\
\hline C4 & 325.46 & 272.77 & 364.23 & 321.75 & 451.27 & 1.19 & 0.89 & 1.01 & 0.72 \\
\hline C5 & 310.02 & 272.77 & 364.23 & 321.75 & 386.50 & 1.13 & 0.85 & 0.96 & 0.80 \\
\hline
\end{tabular}

\section{Conclusions}

A numerical investigation based on the nonlinear finite element analysis has been conducted to assess the influence of stirrups configuration on the performance of exterior joints. Different beam-column connections with different configurations of joint stirrups, have been modeled. The performance of exterior beam-column connection was found dependent on the layout, position and the volume of joint stirrups. From the obtained results, the following remarks can be concluded.

1. The performance of the beam-column connection was found dependent on the orientation and shape of the cross ties, where an increase in both the joint strength and deformation capacity is obtained using straight cross ties in the considered direction or a polygon cross tie. However, the orientation of the straight cross ties in the perpendicular direction improved the deformation capacity.

2. The provision of cross ties, regardless of their orientation, has a significant influence on the deformation capacity up to a volumetric ratio of $1.5 \%$; beyond this limit, no considerable increase in the ultimate deformation can be achieved.

3. The contribution of the cross ties, with consideration of their layout, to the joint shear strength is pronounced; therefore, it is recommended to satisfy the minimum joint reinforcement ratio using both the outer stirrups and cross ties instead of using the outer stirrups only.

4. The use of cross ties in the form of two crossed rectangular ties or a polygonal cross tie is the most efficient practical solution in which the maximum spacing between the stirrups can be considerably increased without affecting the joint performance.

5. The assumption of stirrups yielding in most available analytical models and codes is not safe and needs some revision since the stirrups do not necessarily reach the yield stress.

\section{References}

[1] ACI 318-19 Committee. Building code requirements for structural concrete (ACI 318-19) and commentary. American Concrete Institute, Farmington Hills, Michigan, 2019. 
[2] ACI-ASCE Committee 352R. Recommendations for Design of Beam-Column Connections in Monolithic Reinforced Concrete. American Concrete Institute, Farmington Hills, Michigan, 2002.

[3] Al-Osta MA, Khan U, Baluch MH, Rahman MK (2018), "Effects of variation of axial load on seismic performance of shear deficient RC exterior BCJs." International Journal of Concrete Structures and Materials 12(1): 1-20.

[4] Asha P, Sundararajan R (2018), "Effect of confinement on the seismic performance of reinforced concrete exterior beam-column joints." Australian Journal of Structural Engineering 19(1): 59-66.

[5] Aslani F, Jowkarmeimandi R (2012), "Stress-strain model for concrete under cyclic loading." Magazine of Concrete Research 64(8): 673-685.

[6] Atta AE, Taher SE, Khalil AH, El-Metwally SE (2003), "Behaviour of reinforced high-strength concrete beam-column joint. Part 1: experimental investigation." Structural Concrete 4(4): 175-183.

[7] Bakir PG, Boduroğlu HM (2002), "A new design equation for predicting the joint shear strength of monotonically loaded exterior beam-column joints." Engineering structures 24(8): 1105-1117.

[8] Dabiri H, Kaviani A, Kheyroddin A (2020), "Influence of reinforcement on the performance of non-seismically detailed RC beam-column joints." Journal of Building Engineering (31): 101333.

[9] El-Metwally SE, Chen WF., Structural concrete: strut-and-tie models for unified design. CRC Press, Boca Raton, 2017.

[10] EN 1998-1. Eurocode 8: Design of structures for earthquake resistance Part 1: General rules, seismic actions and rules for buildings. The European Union Per Regulation 305/2011, Directive 98/34/EC, Directive 2004/18/EC, Brussels, 2004.

[11] Hanson NW, Connor HW (1967), "Seismic resistance of reinforced concrete beamcolumn joints." Journal of the structural Division 93(5): 533-560.

[12] Hegger J, Sherif A, Roeser W (2003), "Nonseismic design of beam-column joints.” Structural Journal 100(5): 654-664.

[13] Hwang SJ, Hung-Jen L, Liao TF, Kuo-Chou W, Tsai HH (2005), "Role of hoops on shear strength of reinforced concrete beam-column joints." ACI Structural Journal 102(3): 445-453.

[14] Jankowiak T, Lodygowski T (2005), "Identification of parameters of concrete damage plasticity constitutive model." Foundations of Civil and Environmental Engineering 6(1): 53-69.

[15] Kaung JS, Wong HF (2011), "Effectiveness of horizontal stirrups in joint core for exterior beam-column joints with nonseismic design." Procedia Engineering 14: 3301-3307.

[16] Lu X, Urukap TH, Li S, Lin F (2012), "Seismic behavior of interior RC beamcolumn joints with additional bars under cyclic loading." Earthquake and Structures 3(1): 37-57. 
[17] Mahmoud MH, Afefy HM, Kassem NM, Fawzy TM (2014), "Strengthening of defected beam-column joints using CFRP.” Journal of Advanced Research 5(1): 6777.

[18] Najafgholipour MA, Arabi AR (2021), "Finite-Element Study on the Behavior of Exterior Reinforced Concrete Beam-to-Column Connections with Transverse Reinforcement in the Joint Panel." Practice Periodical on Structural Design and Construction 26(1): 04020050.

[19] Paulay T, Park R, Priestley MJN (1978), "Reinforced Concrete Beam-Column Joints under Seismic Actions.” ACI Journal Proceedings 75(11): 585-593.

[20] Paulay T, Park R., "Joints in reinforced concrete frames designed for earthquake resistance." Research Report 84-9. Department of Civil Engineering, University of Canterbury Christchurch, New Zealand, 1984.

[21] Rajagopal S, Prabavathy S (2014), "Exterior beam-column joint study with nonconventional reinforcement detailing using mechanical anchorage under reversal loading." Sadhana, 39(5): 1185-1200.

[22] Saatcioglu M, Mitchell D, Tinawi R, Gardner NJ, Gillies AG, Ghobarah A, Anderson DL, Lau D (2001), "The August 17, 1999, Kocaeli (Turkey) earthquake damage to structures." Canadian Journal of Civil Engineering 28(4): 715-737.

[23] Simulia. Abaqus Analysis User's Guide. Dassault Systèmes Simulia Corp, Providence, RI, USA, 2014.

[24] Thorenfeldt E, Tomaszewicz A, Jensen JJ (1987), "Mechanical properties of high strength concrete and application to design." Proceedings of the Symposium: Utilization of High-Strength Concrete, Stavanger, Norway, June 1987, Tapir, Trondheim: 149-159.

[25] Tsonos AG (2007), "Cyclic Load Behavior of Reinforced Concrete Beam-Column Subassemblages of Modern Structures.” ACI Structural Journal: 104(4) 468-478.

[26] Ugale AB, Khante SN (2020), "Role of different types of varying hoops reinforcement in RC beam-column joint performance." Materials Today: Proceedings 27: 1590-1595.

[27] Vollum RL, Newman JB (1999), "The design of external, reinforced concrete beamcolumn joints." Structural engineer 77(23\&24): 21-27.

[28] Wight JK, MacGregor JG., Reinforced Concrete: Mechanics and Design. Pearson Education, Inc., Upper Saddle River, New Jersey, 2012. 